\title{
Crônicas da Casa Assassinada: reflexões acerca do espaço literário e de leitura
}

\author{
Bárbara Del Rio Araújo ${ }^{1}$
}

\section{Resumo}

Esse trabalho pretende refletir sobre o espaço literário na obra Crônicas da Casa Assassinada, observando que esse não se limita à percepção das características físicas da "casa", os lugares de trânsito dos sujeitos ficcionais ou a representação aristocrática mineira em decadência. Para além disso, o espaço das Crônicas pode sugerir o debate sobre a interação entre a instância receptiva e os procedimentos narrativos. Nesse aspecto, a obra de Lúcio Cardoso se mostra representativa de como o espaço discursivoliterário é espaço de indeterminação que propicia diferentes leituras.

Palavras-Chave: Espaço; Leituras, Crônicas da Casa Assassinada.

\begin{abstract}
This essay intends to reflect about the literary space in Crônicas da Casa Assassinada, noticing that it is not limited to the perception of house characteristics, the fiction subject places or the decadent mineira aristocracy. Beyond this, the Crônicas space can propose the discussion about the relation between the receptive instance and the narrative procedures. In this sense, Lucio Cardoso book seems representative of discursive and literary space as indetermination, which propitiates different kind of interpretation.
\end{abstract}

Key-Words: Space, Readings; Crônicas da Casa Assassinada.

\section{A Casa e suas implicações espaciais}

A obra Crônicas da Casa Assassinada foi publicada em 1959 e compreendida pela fortuna crítica como um romance, cuja perscrutação se fazia no aspecto psicológico dos personagens. Muito se falou sobre o aspecto intimista que conduzia a narrativa, enfatizando a rememoração dos personagens e a descrição da casa onde habitava a família Menezes ${ }^{2}$. Entrelaçada a essa perspectiva, havia ainda outra vertente crítica que

\footnotetext{
${ }^{1}$ UFMG - Universidade Federal de Minas Gerais; FALE- Faculdade de letras; Belo Horizonte; Minas Gerais; Brasil; barbaradelrio.mg@gmail.com

${ }^{2}$ Ver: BUENO, Luis. Uma história do romance de 30. São Paulo: Ed. UNICAMP, 2006.

Revista Leitura V.2 no 54 - Júlio/Dez 2014 - Número temático: Leituras interartes. Crônicas da Casa Assassinada: reflexões acerca do espaço literário e de leitura Bárbara Del Rio Araújo - p. 38-50 
compreendia a obra como uma metonímia da derrocada moral da família mineira, destacando assim o aspecto regional e social ${ }^{3}$.

Diante dessas vertentes, a obra de Lúcio Cardoso foi analisada pelo seu caráter espacial: uma parte da crítica procurou perceber como o ambiente da "casa", os elementos do cenário e os lugares de trânsito dos personagens projetava as emoções e as experiências dos sujeitos ficcionais; e, a outra parte, embasada nos aspectos socioculturais, procurou perceber como o espaço ficcional da família decadente poderia representar uma conjuntura histórica, econômica, cultural e ideológica brasileira.

Os trabalhos de Luis Eduardo da Silva Andrade e Enaura Quixabeira Rosa e Silva, por exemplo, vão em direção à primeira seara, pois buscam na materialidade dos objetos constituintes da casa indícios para as ações e constituições físicas e psicológicas dos personagens. Tomando como respaldo teórico a obra $O$ sistema de objetos, de Jean Baudrilard, esses estudiosos procuram perceber como o simbolismo dos objetos metaforizam a estruturação performática daqueles sujeitos e daquela família. Nesse sentido, o cristal dos adereços, que adornam a casa, é percebido como a perpetuação do poderio da família aristocrata. A fragilidade do material é, por sua vez, também associada ao momento de decadência com que essa instituição está passando.

Ao fazer uma relação entre os quarto de cada um dos três irmãos - Valdo, Timóteo e Demétrio -, esses trabalhos ainda exploram como que a posição geográfica em relação à planta da casa representa realidades e personalidades diversas em desagregação.

Os trabalhos de Cássia dos Santos e João Batista Cardoso podem ser relacionados à segunda vertente crítica, pois procuram demonstrar como a espacialidade da casa se torna uma representação do nacional. Para esses estudiosos, a desagregação da estrutura patriarcal da família Menezes coincide com o processo de modernização brasileira que é estilizado na obra. Nesses estudos, a intenção é verificar como a história da família Menezes estetiza a derrocada do sistema aristocrático brasileiro frente ao início da ascensão burguesa, representada alegoricamente pela personagem Nina.

Do ponto de vista desse artigo, esses dois vieses de interpretação do espaço e também da obra nos parece complementares, mas nem todo suficiente. Há de se

\footnotetext{
${ }^{3}$ Ver: CARELLI, Mario. A recepção crítica. In: CARDOSO, Lúcio. Crônicas da Casa Assassinada. (edição crítica). São Paulo: ALLCA XX, 1997.

Revista Leitura V.2 no 54 - Júlio/Dez 2014 - Número temático: Leituras interartes. Crônicas da Casa Assassinada: reflexões acerca do espaço literário e de leitura Bárbara Del Rio Araújo - p. 38-50 
contemplar ainda a pungência dessa obra como um espaço em construção, que não é determinado pelos objetos da casa nem mesmo pela referência nacional. A proposta é pensar o espaço literário de Crônicas fora da índole naturalizante, reivindicando a sua atuação reflexiva, que se coloca, se questiona, e se reorienta:

\begin{abstract}
As correntes formalistas e estruturalistas tendem a considerar irrelevante a atribuição de valor "empírico", "mimético", ao espaço como categoria literária; e a defender a existência da espacialidade da própria linguagem. Na direção oposta, as correntes sociológicas ou culturalistas ocupam-se do espaço segundo o viés da representação, ou seja, com o conteúdo social - reconhecível extratextualmente - que se projeta no texto. (...) A terceira posição é que há, hoje, um renovado interesse pelos problemas e potencialidades do conceito de espaço. (...) Pode-se afirmar, em linhas muito gerais, que o espaço deixou de ser tratado como pano de fundo absoluto do universo, e também que, na contramão do legado kantiano, deixou de ser aceito pacificamente como categoria a priori da percepção. (BRANDÃO, 2013, p.48)
\end{abstract}

Essa "virada espacial", que propõe um novo modo de pensar o espaço, propõe também uma identificação particularizadora dos planos que perpassam o texto literário. Esse abandona a perspectiva empirista, fixa e substancialista para alcançar uma perspectiva radicalmente relacional. Trata-se, pois de uma visada que coloca em suspeita (e em suspensão) as hierarquias, investindo na transcendência de se pensar o espaço literário simultaneamente como um sistema de organização e de significação ilimitado. Diante dessa mudança, pode-se afirmar que o espaço literário é um espaço da indeterminação, que não é apriorístico, mas um constructo, sendo impossível encontrálo, mas que é preciso construí-lo e experimentá-lo.

Ao tentar investigar o espaço de uma obra literária, é importante perceber que os sentidos a ele atribuídos se dão a partir da experiência da ação da leitura, que sugere diferentes modos de deslocamentos. Nesse aspecto, é importante pensar a obra não como algo "que é”, mas que "pretende ser". Há de se concebê-la no sentido mais amplo da atividade fictícia, assegurando conceitos provisórios e destinados a serem posteriormente substituídos ou corrigidos. (VAIHINGER, 2011, p.224)

Diante dessa fluidez do espaço literário, a operação de leitura se constitui como um caminho investigativo onde se inicia uma transgressão dos limites e paradigmas, suspendendo-os, incorporando-os na configuração de um imaginário e evidenciando que

Revista Leitura V.2 no 54 - Júlio/Dez 2014 - Número temático: Leituras interartes. Crônicas da Casa Assassinada: reflexões acerca do espaço literário e de leitura Bárbara Del Rio Araújo - p. 38-50 
o significado do texto não está somente selado nele, mas também no ato de leitura. Nesse aspecto, a pretensa determinação interpretativa é invadida pela experiência do homem, lançado no propósito de especular novas perspectivas sobre os modos já consagrados:

\begin{abstract}
A obra mimética, portanto, é necessariamente um discurso com vazios (ISER, 1976), o discurso com o significante errante, em busca dos significados que o leitor lhe emprestará. Os significados então alocados sempre serão transitórios, cuja mutabilidade sempre estará em correspondência com o tempo histórico do receptor. Por essa intervenção indispensável do receptor, o produto mimético é sempre um esquema, algo inacabado, que sobrevive enquanto admite a alocação de um interesse diverso do que o produziu. (COSTA LIMA, 2011, p.308)
\end{abstract}

Este trabalho tem o intuito de analisar de maneira dinâmica a obra Crônica da

Casa Assassinada a fim de mostrar suas potencialidades e, por consequência, sua irredutibilidade às linhas interpretativas referencialistas que a fortuna crítica tem traçado.

\title{
A indeterminação espacial da casa e a expansão da leitura
}

A obra Crônicas da Casa Assassinada é uma narrativa construída por fragmentos de diários, cartas, confissões, livro de memórias, narrações e depoimentos. Através desses textos, os personagens são referenciados uns pelos outros e tomamos conhecimentos dos seus nomes, características físicas e psicológicas. Passamos ainda a conhecer a história da casa da família Menezes desde os tempos passados até a chegada de Nina e seu falecimento.

De modo não linear nem mesmo cronológico, a história é exposta pelo núcleo familiar, por amigos e também por prestadores de serviço da família Menezes. Relatos dos irmãos Valdo e Demétrio se misturam aos relatos de Timóteo, no seu livro de memórias. Acrescenta-se ainda as confissões das noras Nina e Ana. Conta-se também com o diário de André, suposto filho de Valdo e Nina, e da governanta Betty. O farmacêutico, o médico e o Padre Justino também constroem seus pontos de vista,

Revista Leitura V.2 no 54 - Júlio/Dez 2014 - Número temático: Leituras interartes. Crônicas da Casa Assassinada: reflexões acerca do espaço literário e de leitura Bárbara Del Rio Araújo - p. 38-50 
sendo que esses dois últimos deixam transparecer que escrevem a pedido de um desconhecido, que organizaria as demais vozes e tentaria explicar essa história misteriosa:

\begin{abstract}
Sim, resolvi atender ao pedido dessa pessoa. Não a conheço nem sequer imagino por que colige tais fatos, mas imagino que realmente seja premente o interesse que a move. $\mathrm{E}$ ainda mais do que isto, acredito que qualquer que seja o motivo desta premência, só pode ser um fato abençoado por Deus, pois a última das coisas a que o TodoPoderoso nega seu beneplácito, é a eclosão da verdade. Não sei o que essa pessoa procura, mas sinto nas palavras com que solicitou meu depoimento uma sede de justiça. E se acedo afinal - e inteiramente ao seu convite, é menos pela lembrança total dos acontecimentos tantas coisas se perdem com o correr dos tempos... - do que pelo vago desejo de restabelecer o respeito à memória de um ser que muito pagou neste mundo, por faltas que nem sempre foram inteiramente suas. (CARDOSO, 2008, p. 495)
\end{abstract}

Percebe-se que Padre Justino escreve a um destinatário, cuja missão seria coletar os relatos e evidenciar o drama da família Menezes. Contudo, a verdade daquela história estaria longe de ser resolvida. Conforme exposto no trecho acima, o relator e o próprio o interlocutor silencioso demonstram dúvidas diante do que é relatado. As informações carecem de verdade e o que se observa é inúmeras tentativas de montagem desse quebra-cabeça indecifrável e indeterminado.

A narrativa da obra, de maneira geral, é formada por suposições e uma ambiguidade pulsante que exige a mediação do leitor. $\mathrm{O}$ suposto adultério entre Nina e o jardineiro Alberto, a paternidade de André, o caso incestuoso entre Nina, André e Ana são lacunas aonde a ação de leitura se conduz. O mistério ainda se faz presente em relação à morte do jardineiro e sobre a arma utilizada no crime. Como o título da obra sugere, há um assassinato obscuro e uma arma que passa por diversas mãos.

Em um caleidoscópio de impressões, o revólver de madrepérolas, adquirido do farmacêutico por Demétrio com o suposto propósito de espantar os animais que rondavam a fazenda, reaparece em várias cenas. Ele está presente, por exemplo, no disparo de Valdo, quando ouve sobre a partida de Nina em direção ao Rio de Janeiro. A ambiguidade e a suposição em relação ao acontecimento com Valdo se constrói nas seguintes perspectivas: a) o disparo de Valdo fora acidental e foi casuístico o fato de Demétrio armazenar uma arma na casa; b) Valdo tentou suicidio, visto estar amargurado Revista Leitura V.2 no 54 - Júlio/Dez 2014 - Número temático: Leituras interartes. Crônicas da Casa Assassinada: reflexões acerca do espaço literário e de leitura Bárbara Del Rio Araújo - p. 38-50 
com a partida de Nina e com a suposta traição da esposa com o jardineiro; c) o fato não fora acidental, mas sim uma tentativa de Demétrio acabar com a vida do irmão. Essa última opção é defendida com veemência por Nina:

Seria possível [diz Nina] - e já falava quase junto ao meu rosto, num sopro - seria possível que tivesse sido... uma tentativa de assassinato? Não posso deixar de dizer que aquela pergunta, longe de escandalizarme, como que encontrava um eco já familiar em meu espírito. Lembrei-me do olhar que os irmãos haviam trocado assim que o $\mathrm{Sr}$. Valdo voltara a si, da ameaça que fizera de dizer 'o que sabia' e, como nenhuma prova parecesse indicar que se tratava realmente de um 'acidente', não tive a menor dúvida em afirmar que a hipótese do crime não seria descabida. (CARDOSO, 2008, p.71. Grifos meus).

A situação em busca de um culpado e de uma verdade absoluta se complica ainda mais quando, antes de partir para o Rio de Janeiro, Ana vê a cunhada Nina atirar a arma fora da janela. Essa arma seria recolhida por Alberto e se tornaria agente do disparo que encerraria a sua vida. Nesse sentido, Ana coloca Nina como principal suspeita do crime envolvendo Alberto. A personagem suspeita se Nina fora consciente na ação de jogar o revólver ao jardineiro, sabendo que ele, apaixonado, preferiria morrer a conviver coma a sua partida.

A partir da morte de Alberto, Ana guarda a arma e se sente culpada por não ter evitado a morte do jardineiro que amava. Ana sentia ciúmes e preferiu ver Alberto próximo àquele revólver, próximo da morte, a vê-lo junto da cunhada. Agora, ela se confessa, ainda confusa, como cúmplice do assassinato:

No entanto, à medida que o tempo passa, desnorteio-me, não me sinto mais segura do meu direito: saberia ela realmente o que estava cometendo, quando lançara a arma fora? Ah, caso tivesse sido apenas um gesto inconsciente - e era, na verdade, praticamente impossível estabelecer o certo - a culpa retombaria quase inteira sobre meus ombros, e eu seria a criminosa, e não ela. Mas naquele instante, como não ceder à volúpia de jogar e arriscar tudo? Era praticamente minha única oportunidade de destruí-la. (CARDOSO, 2008, p. 168-169).

Um crime, várias versões e vários suspeitos. Contudo, não se pode optar por uma resolução unívoca. Em alguns momentos, nota-se uma polaridade entre as vozes que apoiam e inocentam Nina e as vozes que defendem Demétrio. Timóteo, por

Revista Leitura V.2 no 54 - Júlio/Dez 2014 - Número temático: Leituras interartes. Crônicas da Casa Assassinada: reflexões acerca do espaço literário e de leitura Bárbara Del Rio Araújo - p. 38-50 
exemplo, deixa claro sua aversão pelo irmão e sua cumplicidade pela cunhada. Valdo, que fora casado com ela, e André, seu suposto filho, se mostram cambiantes entre amá-la e condená-la. Ana é a favor do marido Demétrio e deixa evidente seu ódio pela mulher que reinava como soberana na casa dos Menezes. Essa polaridade nunca se desfaz, e tanto Nina como Demétrio são inocentes e culpados, vencedores e vencidos. Ainda que ela morra tomada por um câncer, isso não significa o triunfo de Demétrio, defensor da casa e da moralidade da família Menezes. Para comprovar isso, havemos de nos lembrar do episódio final narrado por Valdo, quando na presença do Barão, Demétrio é sucumbido pela atitude do irmão Timóteo:

\begin{abstract}
Por trás de mim, para os lados onde o barão se achava, rompeu uma espécie de urro vibrante e dolorido, como o de alguém que acabasse de ser mortalmente ferido. Voltei-me, convicto de que alguém acabara de ser atingido por uma punhalada. Mas não vi ninguém, nem percebi coisa alguma, fora a figura de Demétrio, curvo, completamente apoiado à mesa onde se encontrava o caixão. Fora ele quem gritara, não havia a respeito disto a mínima dúvida - e pálido, as mãos no ventre como se procurasse conter um sangue borbulhante que escorresse, era a imagem exata de um homem atingido pela arma do assassino, e que procurasse em vão, menos conter o sangue que o esvaziava, e o deixava inerme sobre a mesa, do que defender, trapo humano, a essência mortal que o compunha (CARDOSO, 2008, p. 499)
\end{abstract}

A aparição de Timóteo vestido de mulher perante o Barão colocava em cheque a condição moral da família Menezes. Demétrio derroca junto da imagem patriarcal e, assim como Nina, se mostra corroído e em queda, como se observou no entrecho.

A leitura crítica sociocultural, que vê nessa obra de Lúcio Cardoso a representação da decadência aristocrata brasileira, costuma interpretar a queda de Demétrio, assim como o enlouquecimento de Timóteo e a deteriorização do espaço da casa, como a dramatização do fim do patriarcalismo rural tendo em vista o contexto de modernização. Essa é representada por Nina, cujos hábitos eram citadinos e não suportava a vida na fazenda: "Essa gente calada e feia que viera observando no trem. (...) Creio que foi essa aversão que levantou os alicerces do desentendimento entre a patroa e o Sr. Demétrio, de natureza tão arraigadamente mineira (CARDOSO, 2008, p.62)

Revista Leitura V.2 no 54 - Júlio/Dez 2014 - Número temático: Leituras interartes. Crônicas da Casa Assassinada: reflexões acerca do espaço literário e de leitura Bárbara Del Rio Araújo - p. 38-50 
Contudo, como podemos perceber, a polarização não se resolve com a queda de Demétrio e da família. A imolação moral do personagem não dimensiona diretamente para o triunfo da modernização, pois Nina, alegoria desse processo, também sucumbe. Deste modo, pensar a obra com essa referencialidade se torna complicado, uma vez que não há uma definição em favor de algum desses personagens. Até mesmo André, que poderia apontar para a continuidade ou a castração da família, se mostra ambivalente, uma vez que não se determina sobre sua origem paternal.

Nesse aspecto, o que existe de permanente na obra é a indeterminação. Não há como tomar partido em favor de um aspecto ou de outro. Nessa narrativa sinuosa, dotada de uma linguagem que se desdobra em descrições líricas e psicológicas, o leitor se vê diante de uma realidade ambígua, onde o referente está "balançado". Confiar, isto é, atribuir verdade a qualquer aspecto do relato é perceber apenas uma parte do imbróglio complexo que a obra nos apresenta.

A vertente crítica que busca ver nos objetos e no espaço da casa uma chave interpretativa para compreender as ações e os personagens também tende a romper a polaridade da narrativa e a cair na limitação referencial. Apropriar-se da simbologia dos objetos para decodificar os personagens e a interpretação pode se tornar ineficaz, pois sabemos da inconstância e da volubilidade desses sujeitos ficcionais. No trecho abaixo, percebemos como a personagem se desvela e se compõe de tudo e nada, sendo, pois indeterminada:

Tudo se arquiteta em mim, a mentira me torna redivivo. Continuo imaginando que logo após descerei as escadas da Chácara e irei catar violetas pelos canteiros mais distantes (...) Mas regresso devagar ao mundo que me rodeia. Imagens derrotadas. (CARDOSO, 2008, p.22)

Em outro fragmento, nota-se que o relato dos próprios personagens é relativo. Ao dizer sobre a sua história, seu passado e de os outros personagens, todo referente se desestabiliza:

Mas quando não me socorria a imaginação, escavava a lembrança com tal fúria e tal necessidade de encontrar um indicio de sua vida que o revia indistinto como através de um sonho, mas ainda presente. Porque tudo se confundia a tal ponto que eu perdia de vista sua identidade e o próprio nome de Alberto convertia-se num nome idêntico a todos os nomes dos homens (CARDOSO, 2008, p.310)

Revista Leitura V.2 no 54 - Júlio/Dez 2014 - Número temático: Leituras interartes. Crônicas da Casa Assassinada: reflexões acerca do espaço literário e de leitura 
Deste modo, propor que a casa e os objetos que a compõe possam ajudar a esclarecer quem são esses personagens e o mistério que eles guardam é uma tentativa provisória. A ambiguidade do espaço anula esse referente, não sendo possível confiar nos objetos, pois eles se transfiguram e se imiscuem.

A mediação por parte do leitor se coloca como fulcro necessário para se compreender todos os cinquenta e seis fragmentos que entrelaça passado (lembranças) e o momento presente (da escrita e da enunciação). Em relação a esse último, percebe-se um deslocamento temporal capaz de introduzir um aspecto metalinguístico, uma reflexão sobre o fato de narrar:

Pesa-me a consciência, ocultar fatos que poderiam alguns daqueles mistérios que na época abalaram o nosso povoado. Pensando bem este é o motivo que me encontro aqui reajustando sobre o passado essas lentes que apesar de tremulas só procuram servir a verdade. Naturalmente não me é fácil desenterras essas figuras, pois elas se acham visceralmente presas ao que eu próprio fui e as emoções daquele tempo. (CARDOSO, 2008, p.144)

É também por essa reflexão metalinguística que o leitor tem certeza de que aquele relato e as imagens que suscitam são duvidosos. Afinal, nesse vezo reflexivo sobre a capacidade de contar é que o personagem conta que nem tudo sabe e nem tudo viu. É aí, então que a mediação entra de modo mais incisivo e o leitor é chamado a recompor esse espaço do mistério. O texto aparece "como um mundo que ainda há de ser identificado e que é esboçado de modo a incitar o leitor a imaginá-lo e, por fim, interpretá-lo" (ISER, 2002, p.107)

A narrativa de Crônicas da Casa Assassinada expõe a esfera de recepção a um plano multiperspectivo em que cada narrador exerce uma função hermenêutica de interpretação dos fatos. Cada personagem reivindica a posse da verdade e o leitor precisa construir a sua versão, já que nenhum relato lhe parece condizente. O leitor, envolvido nessa tessitura, torna ainda mais dinâmico o eixo textual, recompondo os fragmentos e atualizando as versões dos personagens, cruzando as referências e percebendo que ali a narrativa é mévl e movente pela leitura:

Esta concepção do texto está em conflito direto com a noção tradicional de representação, à medida que mimesis envolve a referência a uma 'realidade' pré-dada, que se pretende estar representada. (...) Desde o advento do mundo moderno há uma

Revista Leitura V.2 no 54 - Júlio/Dez 2014 - Número temático: Leituras interartes. Crônicas da Casa Assassinada: reflexões acerca do espaço literário e de leitura Bárbara Del Rio Araújo - p. 38-50 
tendência clara em privilegiar-se o aspecto performático da relação autor-texto-leitor, pelo qual o pré-dado não é mais visto como um objeto de representação, mas sim como o material a partir do qual algo novo é modelado. (ISER, 2002, p.105)

O que se nota é a perspectiva irredutível da obra à referencialidade dos objetos, da casa ou do espaço nacional. Prevalecem na narrativa, como afirma Alfredo Bosi, os fantasmas da transgressão que assediam os personagens, as verdades, as consciências e todo o espaço. (BOSI,1967,p.628)

Este trabalho buscou evidenciar que, ao lado das vertentes críticas mais tradicionais, seria necessário acrescentar uma perspectiva que refletisse sobre a indeterminação na obra. Deste modo, tentou-se estabelecer as limitações das perspectivas referencialistas e destacar a importância de se conceber espaço literário das Crônicas como uma abstração, uma hipótese plausível para organizar uma experiência. Nesse aspecto, elegeu-se o leitor e a ação de leitura e de experimentação, como fundamentos elementares na movimentação das molduras da narrativa.

\section{Considerações Finais}

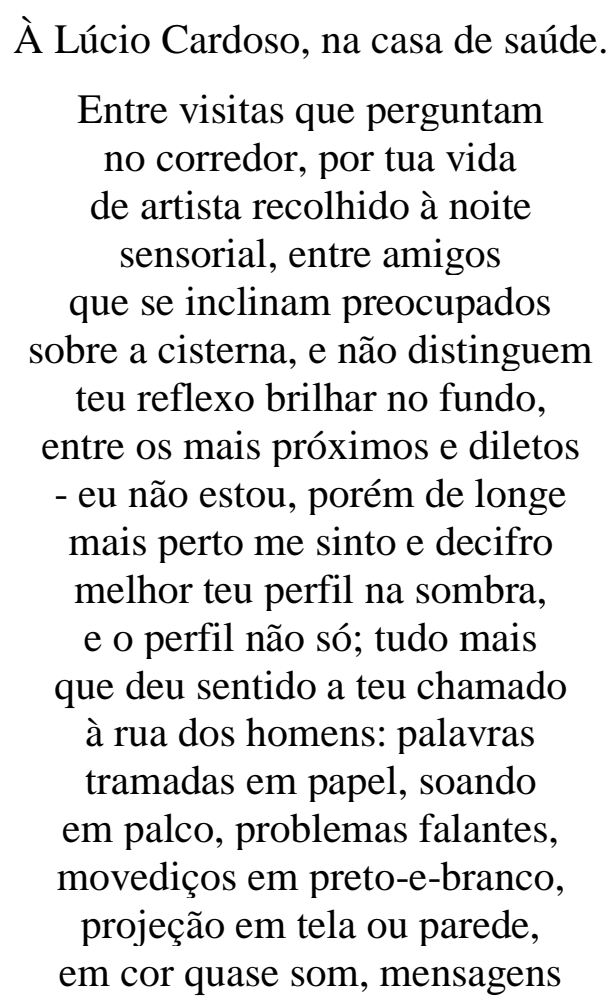

Revista Leitura V.2 no 54 - Júlio/Dez 2014 - Número temático: Leituras interartes. Crônicas da Casa Assassinada: reflexões acerca do espaço literário e de leitura 


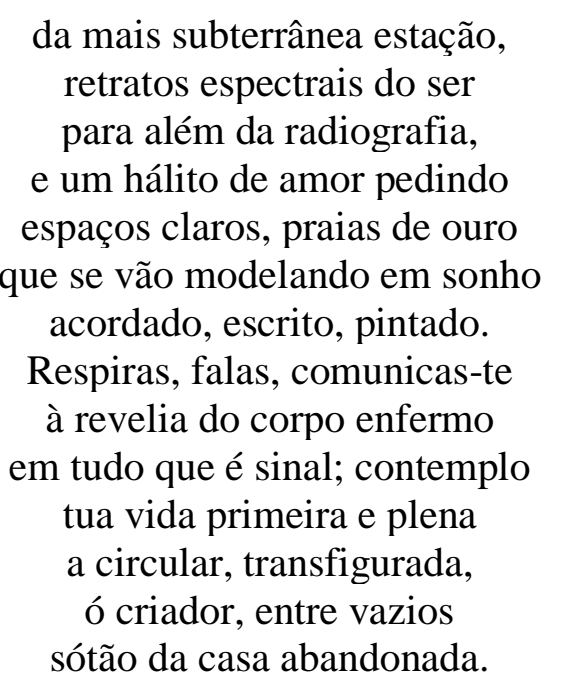

O poema supracitado foi publicado no jornal Correio da Manhã em 20 de setembro de 1968 e é uma homenagem de Carlos Drummond de Andrade ao amigo Lúcio Cardoso. A referência à obra Crônicas da Casa Assassinada aparece discretamente no conteúdo do texto e indiretamente no último verso, onde se explicita "sótão da casa abandonada". Se analisarmos com atenção, o conjunto dos versos pode se tornar elucidativo não só da história biográfica do autor como também da obra em estudo.

Para Drummond, Cardoso "deu sentido à rua dos homens", estetizando-os por meio de "palavras", "problemas movediços" e "mensagens da mais subterrânea estação". Em uma perspectiva humanista e ao mesmo tempo arruinadora, quase niilista, o autor de Maleita consegue recriar o caráter irresoluto da condição humana bem como a fluidez das certezas que a cerca.

Como fora percebido nessa análise, a representação do homem em Crônicas da Casa Assassinada não se dá de maneira homogênea. Ao contrário, esse ser humano é ambivalente e contraditório. Todas as personagens e suas ações apontam para um movimento cambiante, em que não é possível obter uma essência para defini-las. Assim como o poema sugere, há, nas obras de Lúcio Cardoso, em especial nessa selecionada, uma busca por notar os "retratos espectrais do ser para além da radiografia".

Deste modo, propusemos aqui, uma tentativa de realização dessa busca, reclamando a superação da condição referencial na interpretação do espaço e a instalação de uma perspectiva que investe no prisma da instabilidade e da indeterminação. Nesse aspecto, a partir das Crônicas e da sua análise pela fortuna Revista Leitura V.2 no 54 - Júlio/Dez 2014 - Número temático: Leituras interartes. Crônicas da Casa Assassinada: reflexões acerca do espaço literário e de leitura Bárbara Del Rio Araújo - p. 38-50 
crítica, tentamos demonstrar que uma perspectiva importante para o entendimento do livro seria aquela que tomaria o espaço literário à luz do desordenado, repleto de incertezas e ambiguidades.

A partir disso, introduzimos a discussão sobre a importância do campo da recepção em construir/ desconstruir e fomentar as linhas interpretativas, efetuando o deslocamento e a transposição dos lugares habituais e sobretudo desmontando a ideia tradicional de representação e espacialidade.

\section{4 - Referências}

ANDRADE, Carlos Drummond de. Lúcio Cardoso na casa de saúde. In: Tribuna da Imprensa. Rio de Janeiro, 4 mar. 1968

ANDRADE, Luis Eduardo da Silva. Casa e família: uma simbiose do mal em Poe e Lucio Cardoso. Disponível em:

www.uniabeu.edu.br/publica/index.php/RE/article/view/655/pdf_283. Acesso em 30/04/2014

BACHELARD, Gaston. O obstáculo substancialista. In: BACHELARD, Gaston. A formação do espírito científico. Rio de Janeiro: Contraponto, 2010, p.121-161

BOSI, Alfredo. Um grande folhetim tumultuosamente filosófico. In: CARELLI, Mario. A recepção crítica. In: CARDOSO, Lucio. Crônicas da Casa Assassinada. (edição crítica). São Paulo: ALLCA XX, 1997, p. 628-640.

BRANDÃO, Luís Alberto; OLIVEIRA, Silvana Pessoa de. Sujeito, tempo e espaço ficcionais: introdução à teoria da literatura. São Paulo: Martins Fontes, 2001

BRANDÃO, Luís Alberto. Teorias do espaço literário. São Paulo: Perspectiva, 2013. BUENO, Luis. Uma história do romance de 30. São Paulo: Ed. UNICAMP, 2006. CARDOSO, Lúcio. Crônicas da Casa Assassinada. 7ed. Rio de Janeiro: Civilização Brasileira, 2008.

CARDOSO, João Batista. Um mapa da História sobre o mapa da ficção. Goiânia: Ed. UCG, 2009.

CARELLI, Mario. A recepção crítica. In: CARDOSO, Lucio. Crônicas da Casa Assassinada. (edição crítica). São Paulo: ALLCA XX, 1997, p. 628-640.

COSTA LIMA, Luiz. Representação social e mímesis. In: COSTA LIMA, Luiz. Escritos de Véspera. Florianópolis: Ed UFSC, 2011, p.285-312.

ISER, Wolfgang. O jogo do texto. In: COSTA LIMA, Luis (org). A literatura e o leitor. 2ed. São Paulo: Paz e Terra, 2002, p. 105-118.

KOSELLECK, Reinhart. Espaço de experiência e horizonte de expectativa: duas categorias históricas. In: KOSELLECK, Reinhart. Futuro passado: contribuição à semântica dos tempos históricos. Rio de Janeiro: Contraponto, 2006, p.305-327. POULET, Georges. O espaço proustiano. Rio de Janeiro: Imago, 1992

SANTOS, Cássia dos. Polêmica e controvérsia em Lúcio Cardoso-Campinas. São Paulo: FAPESP, 2001.

SILVA, Enaura Quixabeira Rosa e. A alegoria da ruína: uma análise da Crônica da casa assassinada. Maceió: HD Livros, 1995.

Revista Leitura V.2 no 54 - Júlio/Dez 2014 - Número temático: Leituras interartes. Crônicas da Casa Assassinada: reflexões acerca do espaço literário e de leitura Bárbara Del Rio Araújo - p. 38-50 
VAIHINGER, Hans. A filosofia do como se. Trad. Johannes Kretschmer. Chapecó: Ed. Unochepecó, 2011.

Revista Leitura V.2 no 54 - Júlio/Dez 2014 - Número temático: Leituras interartes. Crônicas da Casa Assassinada: reflexões acerca do espaço literário e de leitura Bárbara Del Rio Araújo - p. 38-50 